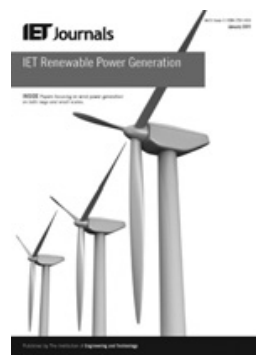

ISSN 1752-1416

\title{
Maximising revenue for non-firm distributed wind generation with energy storage in an active management scheme
}

\author{
Simon Gill' ${ }^{1}$ Edward Barbour', I.A. Grant Wilson', David Infield ${ }^{1}$ \\ ${ }^{1}$ Centre for Doctoral Training in Wind Energy Systems, Department of Electronic and Electrical Engineering, \\ University of Strathclyde, Glasgow \\ ${ }^{2}$ Institute for Energy Systems, University of Edinburgh, Edinburgh \\ ${ }^{3}$ Department of Chemical and Biological Engineering, University of Sheffield, Sheffield \\ E-mail: simon.gill@eee.strath.ac.uk
}

\begin{abstract}
The connection of high penetrations of renewable generation such as wind to distribution networks requires new active management techniques. Curtailing distributed generation during periods of network congestion allows for a higher penetration of distributed wind to connect, however, it reduces the potential revenue from these wind turbines. Energy storage can be used to alleviate this and the store can also be used to carry out other tasks such as trading on an electricity spot market, a mode of operation known as arbitrage. The combination of available revenue streams is crucial in the financial viability of energy storage. This study presents a heuristic algorithm for the optimisation of revenue generated by an energy storage unit working with two revenue streams: generation-curtailment reduction and arbitrage. The algorithm is used to demonstrate the ability of storage to generate revenue and to reduce generation curtailment for two case study networks. Studies carried out include a single wind farm and multiple wind farms connected under a 'last-in-first-out' principle of access. The results clearly show that storage using both operating modes increases revenue over either mode individually. Moreover, energy storage is shown to be effective at reducing curtailment while increasing the utilisation of circuits linking the distribution and transmission networks. Finally, renewable subsidies are considered as a potential third revenue stream. It is interesting to note that under current market agreements such subsidies have the potential to perversely encourage the installation of inefficient storage technologies, because of increased losses facilitating greater "utilisation" of renewable generation.
\end{abstract}

\section{Introduction}

The integration of wind power is creating challenges for power system operators in many countries. The characteristics of wind generation and other renewables mean that new methods of network management are required. Wind generation is time variable, to an extent unpredictable, generally poorly correlated with demand and has a relatively low capacity factor. The small size of many wind developments and the geographical distribution of the resource means that many wind developments connect at the distribution rather than transmission level; this is driven by lower costs or physical accessibility [1].

Traditionally, distributed generation has received firmconnection contracts allowing a 'fit-and-forget' philosophy to be applied. Firm-connections guarantee network access up to the rated power of the generator at all times, but the low capacity factors of wind farms, usually between 0.2 and 0.5 , mean that awarding firm connections places unnecessarily strict limits on the total capacity that can connect. Several distribution networks in the UK have reached the maximum capacity of firmly connected generation, for example, in the Orkney Isles [2].

An alternative management philosophy is Active Network Management (ANM) in which generators and other network components are managed in real time to reach specified goals. These techniques have been shown to be successful in managing voltage and thermal limits with increased distributed generation [3, 4]. Two applications of ANM are generation curtailment and the use of Energy storage systems (ESSs). Generation curtailment allows additional distributed generation to connect with the agreement that under specified network conditions the new generator may have to reduce output or disconnect entirely. A generation curtailment scheme is in operation on the Orkney distribution network [2] and manages thermal and voltage limits across the network including an undersea connection to the transmission network.

Connections on a generation curtailment scheme are described as non-firm connections as they do not guarantee network access at all times. Generation curtailment and other ANM techniques provide an alternative to reinforcing 
the network and can provide a lower cost method of increasing network capacity for both distributed generation and demand.

From the generators perspective, curtailment can mean a reduction in revenue and non-firm connections increases uncertainty in future revenue. Combining ESS with wind farms can reduce curtailment, mitigate the risks associated with non-firm connections and use the ESS unit to raise revenue in its own right. For example, ESSs can be used to reduce curtailment by storing energy that is later discharged into the network during periods of low-congestion. In addition, an ESS can carry out arbitrage with an electricity spot market, buying when the market price is low and selling when it is high.

This ability of an ESS to access multiple revenue streams is noted by several reports as an important factor in financial viability of expensive ESS technologies [5]. Examples of the value that an ESS can bring to a power system include its ability to carry out load-following, peak-shaving, reserve provision, investment deferral and mitigation of variability $[5,6]$. ESS technologies of the scale required for bulk time-shifting of energy are currently expensive. Estimates of the cost of sodium-sulphur batteries are in the range of $£ 1.3-£ 2.5$ million $[7,8]$ and this expense has limited the application of ESSs to date. Table 1 provides a summary of some technologies and their largest installations worldwide. Developing technologies such as super capacitors are yet to be deployed at sizes suitable for bulk power shifting, whereas more developed technologies such as lead acid batteries have a track record of multi-MW installations. The key characteristics of ESSs include charging and discharging efficiencies and self-discharge, that is any effect where energy either leaks or is required in operation of the store itself (e.g. through heating of sodium-sulphur batteries).

The role of an ESS operating in a single application has been investigated through several optimisation studies. In [9], a generation curtailment scheme is set up and ESSs are sized based on the maximum curtailed generation. This study assumes that all generation curtailment will occur at night-time, and therefore a simple ESS schedule is implemented based on night-time charging, daytime discharging and a full cycle within each $24 \mathrm{~h}$ period. Although this is true for small penetrations of non-firm wind, as the wind penetration increases, curtailment can occur at any time of the day and a more complex optimisation is required. A fuller solution to this problem is given in [22] where a linear programming optimisation is used to maximise the revenue raised by a wind farm and an ESS unit. The optimisation only allows the ESS to time shift wind farm generation, and does not include self-discharge effects. If self-discharge effects are included, mathematical programming techniques cannot be applied to optimisation, and heuristic optimisation is required. Heuristic-optimisation has been used to investigate hydro-pumped storage in large transmission networks [23] and work on maximisation of energy output from small-scale tidal devices has been carried out in [24]. In [25], a generic heuristic optimisation of ESS is developed for provision of arbitrage on a spot market, this builds up an ESS schedule based on a price signal and the characteristics of the ESS device.

This paper investigates the optimal use of an ESS linked to wind-farms in a curtailment scheme. The ESS is able to access two revenue streams: reduction of generationcurtailment and arbitrage on a spot market. This paper develops an algorithm that finds the optimal combination of these two modes. The method developed is a heuristic optimisation which is an extension of the one presented in [25]. This paper presents three key contributions: (i) the development of a heuristic optimisation algorithm which incorporates two revenue streams and the presentation of two case studies illustrating the use of this algorithm in distribution networks with high penetrations of non-firm wind and ESS; (ii) the effect of wind of ESS penetration on power flows in the circuits joining the distribution and transmission networks; and (iii) a discussion of the interaction of the ESS and renewable energy subsidies.

\section{Description of the models and algorithm}

The algorithm uses a heuristic, stochastic optimisation process to maximise the revenue to an ESS unit. Revenue is generated through buying and selling power on an electricity market, commonly termed arbitrage or through time-shifting curtailed generation from a wind generator with non-firm connection and selling later to the market.

In this paper, the term 'curtailed energy' refers to the difference between curtailed and un-curtailed output. The

Table 1 Existing ESS technologies with an example of their largest implementation

\begin{tabular}{|c|c|c|c|c|c|}
\hline Type of system & Name of System & $\begin{array}{l}\text { Peak } \\
\text { power }\end{array}$ & $\begin{array}{l}\text { Energy } \\
\text { stored }\end{array}$ & Date of use & Reference \\
\hline pumped storage & $\begin{array}{l}\text { Bath County Pumped Storage } \\
\text { Station, USA }\end{array}$ & $\sim 3000 \mathrm{MW}$ & $\sim 33 \mathrm{GWh}$ & $1985-$ & {$[10]$} \\
\hline battery - nicad & GVEA BESS, Fairbanks, USA & $27 \mathrm{MW}$ & 14.6 MWh & $2003-$ & {$[11,12]$} \\
\hline battery - lifep04 & Zhangbei, China & $140 \mathrm{MW}$ & $36 \mathrm{MWh}$ & $2011-$ & [13] \\
\hline battery - lead acid & Chino, California, USA & $14 \mathrm{MW}$ & $40 \mathrm{MWh}$ & 1998-1997 & [14] \\
\hline vanadium redox flow battery & $\begin{array}{l}\text { Gills Onions, Oxnard, California, } \\
\text { USA }\end{array}$ & $600 \mathrm{~kW}$ & $6 \mathrm{MWh}$ & $2010-$ & [15] \\
\hline zinc bromide flow battery & ZBB Energy & $250 \mathrm{~kW}$ & $500 \mathrm{kWh}$ & unknown & [16] \\
\hline supercapacitor & $\begin{array}{l}\text { SITRAS Stationary Energy Storage } \\
\text { (SES), Various }\end{array}$ & $0.7 \mathrm{MW}$ & $2.5 \mathrm{kWh}$ & $2008-$ & [17] \\
\hline flywheel & Stephentown, USA & $20 \mathrm{MW}$ & $5 \mathrm{MWh}$ & $2011-$ & [18] \\
\hline $\begin{array}{l}\text { adiabatic compressed air } \\
\text { energy storage }\end{array}$ & ADELE Project, Germany & $90 \mathrm{MW}$ & $360 \mathrm{MWh}$ & $\begin{array}{l}\text { planned development } \\
2013\end{array}$ & [19] \\
\hline compressed air energy storage & Huntdorf Project, Germany & $290 \mathrm{MW}$ & $\begin{array}{l}\text { uses natural } \\
\text { gas }\end{array}$ & $1978-$ & [20] \\
\hline $\begin{array}{l}\text { superconducting magnetic } \\
\text { energy storage }\end{array}$ & Florida State University (test bed) & $100 \mathrm{MW}$ & $\sim 28 \mathrm{kWh}$ & unknown & [21] \\
\hline
\end{tabular}


cost to the ESS of using curtailed energy is in this case zero (although the algorithm has the option of placing a fixed cost on curtailed energy). Market transactions occur at a spot market price that is time dependant and externally fixed. The algorithm uses historical data for network demand, wind generation and price. The results have two interpretations: (i) optimal operation of the ESS assuming perfect forecast information; (ii) the maximum possible revenue available to a non-firm wind/ESS installation, therefore a value that can be used to benchmark real-time operational strategies.

\subsection{ESS model}

The algorithm employs a generic ESS model. This is defined by the following parameters:

- Maximum power limits for charge and discharge, PLI and PLO.

- Maximum storage capacity, $\mathrm{SOC}_{\max }$ and a minimum state of charge of 0 .

- Charging and discharging efficiency, $\eta_{\text {in }}$ and $\eta_{\text {out }}$.

- Exponential self-discharge with characteristic timescale $\tau$.

The energy transfer during each period, $E_{\text {to store }}(t)$, represents the change of SOC for each period. The energy drawn or delivered to the grid is related to this through charging and discharging efficiencies. The self-discharge affects the SOC of the store by reducing the amount of stored energy over time, so that without additional charging or discharging

$$
\operatorname{SOC}\left(t_{2}\right)=\operatorname{SOC}\left(t_{1}\right)^{\mathrm{e} \frac{\tau_{1}-\tau_{2}}{\tau}}
$$

\subsection{Curtailment scheme model}

The curtailment scheme model is a typical distribution network with distributed generation. The model includes wind with firm and non-firm connections. Faults are not considered and network losses are discounted. The network consists of

- Transmission link circuits (TLCs) with capacity $P_{\text {circuit: }}$ : circuits may include power lines, undersea cables and transformers. These form the connection between the distribution and transmission networks.

- Local demand on the distribution network, $P_{\mathrm{d}}(t)$.

- Maximum firm wind with a generation time series $P_{\mathrm{f}}(t)$.

- Non-firm wind connected under the curtailment scheme $P_{\text {nf }}(t)$. The available output of non-firm generation is curtailed during any time period in which the network does not have the capacity to export the power in question. Network capacity is defined here as local demand plus export capacity. Hence after curtailment is applied, the non-firm generation time-series obeys the inequality

$$
P_{\mathrm{nf}}(t) \leq P_{\mathrm{d}}(t)+P_{\text {circuit }}-P_{\mathrm{f}}(t)
$$

- Accordingly, during any period in which the non-firm wind was forced to reduce its output there is curtailed energy, $E_{\text {curt }}(t)$, available in principle.

\subsection{Optimisation algorithm}

Optimisation is applied to the ESS device and has the objective of maximising the revenue received by ESS while ensuring that all network constraints are maintained. Mathematically, the problem is specified as

$$
\max \sum_{i=1}^{t} E_{\text {to grid }}(t) p(t)
$$

where $p(t)$ is the spot market price and $E_{\text {to grid }}(t)$ is found from

$$
\begin{gathered}
E_{\text {to grid }}(t)=-\eta_{\text {out }} E_{\text {to store }}(t) \text { discharging } \\
E_{\text {to grid }}(t)=-\left(\frac{E_{\text {to store }}(t)}{\eta_{\text {in }}}-E_{\text {used curt }}(t)\right) \text { charging }
\end{gathered}
$$

and $E_{\text {used curt }}$ is the curtailed generation used to charge the store.

The physical constraints of the ESS are its power rating and its maximum and minimum state of charge (SOC). Expressed mathematically these constraints are

$$
\begin{gathered}
-\mathrm{PLO}<\frac{E_{\text {to store }}\left(t_{1}\right)}{\Delta t}<\mathrm{PLO}, \quad \forall t \\
0<\mathrm{SOC}(t)<\mathrm{SOC}_{\max } \quad \forall t
\end{gathered}
$$

Network constraints are defined to ensure that the optimisation avoids overloading the TLCs, in either the import or export directions. To clarify, this imposes the constraint that the ESS cannot charge at a rate greater than the maximum capacity of the TLC $\left(P_{\text {cicuit }}\right)$ plus local wind generation and minus local demand. Similarly, for discharging, it ensures that the power output from the storage device is always less than the rating of the TLC plus the local demand, minus the local wind generation

$$
\begin{aligned}
& -P_{\text {circuit }}+\left\{P_{\mathrm{d}}(t)-P_{\mathrm{nf}}(t)-P_{\mathrm{f}}(t)\right\}<\frac{E_{\text {to grid }}(t)}{\Delta t}<P_{\text {circuit }} \\
& +\left\{P_{\mathrm{d}}(t)-P_{\mathrm{nf}}(t)-P_{\mathrm{f}}(t)\right\} ; \quad \forall t
\end{aligned}
$$

Finally, a constraint is applied to ensure that only available curtailed energy is used

$$
E_{\text {used curt }}(t)<E_{\text {curt }}(t) ; \quad \forall t
$$

The optimisation algorithm iteratively builds a schedule for the ESS device that dictates the charging and discharging rates for each $30 \mathrm{~min}$ period of the time-horizon. In summary: an initial interim schedule is set up with no charging or discharging. A random possible transaction is selected, if the transaction increases revenue and is physically feasible within the optimisation constraints it is accepted and added to the interim schedule. The next iteration starts from this new schedule and the process is repeated until the optimisation converges on an optimal schedule.

A transaction consists of two randomly selected time-periods: $t_{1}$ and $t_{2}$, and an amount of energy, $\Delta E$. The value of $\Delta E$ is the contribution that this specific 


\section{www.ietdl.org}

transaction makes to the time series $E_{\text {to Store }}(t 1)$. The value of $\Delta E$ can be either positive or negative; a positive value of $\Delta E$ represents the case where the store is charged during $t_{1}$ and discharged during $t_{2}$ and a negative value represents the case in which the store discharges during $t_{1}$ and recharges during $t_{2}$. These negative energy transactions are the key to the optimisation and allow the process to correct for previous moves that were sub-optimal.
To test if a potential transaction increases revenue, the cost of charging and the return from discharging are compared. If charging uses curtailed energy, the transaction will definitely increase revenue as charging is at zero cost and prices are always positive. If charging involves buying from the market, a comparison of the spot market prices is undertaken. The increase in price between charging and discharging needs to be enough to cover the efficiency

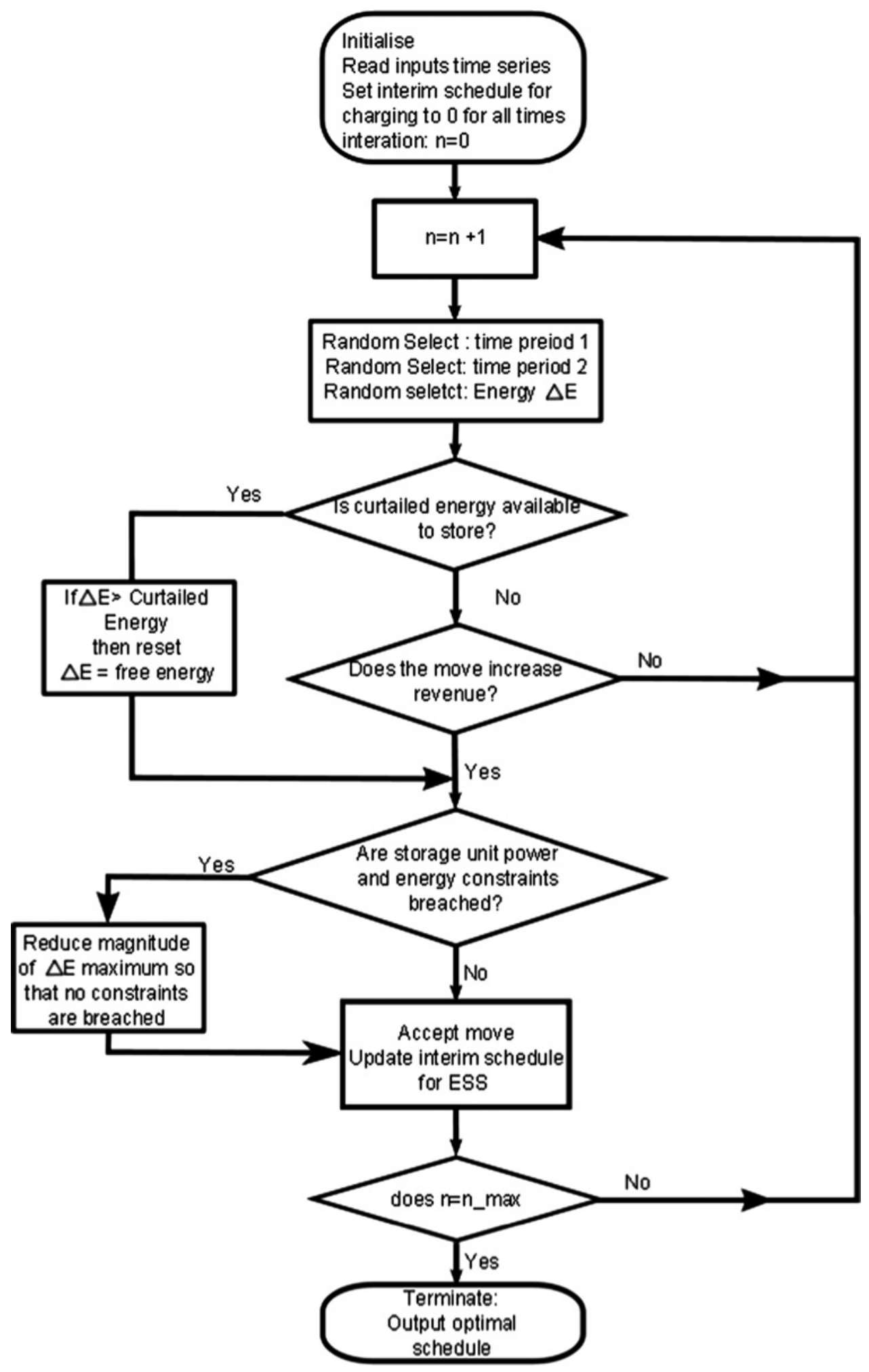

Fig. 1 Flow chart of optimisation 
losses of the store. Hence, for a transaction that charges during period 1 , the ratio of prices needed to fulfil the requirement of a revenue increase is

$$
\frac{p\left(t_{1}\right)}{p\left(t_{2}\right)}<\eta_{\text {in }} \eta_{\text {out }} \mathrm{e}^{\frac{t_{1}-t_{2}}{\tau}}
$$

If this requirement is not met the algorithm abandons the transaction, returns to the existing interim schedule and selects a new potential transaction.

The second requirement is that the transaction is physically viable and the charging, discharging and network constraints are met during periods 1 and 2 and that the SOC constraint is met for all periods between periods 1 and 2. If any of these constraints are breached the algorithm reduces the magnitude of $\Delta E$ until no constraints are breached. If $\Delta E$ has to be reduced to zero, the transaction is abandoned and the algorithm starts a new iteration.

Although each individual transaction effectively moves energy between two time periods, the combined effect of a large number of accepted transactions allows interactions between many different time periods and thus allows the algorithm to converge on the optimal linkages across all time periods.

A flowchart of the optimisation algorithm is given in Fig. 1.

\subsection{Illustrative example}

A short example is provided to allow the reader to understand different transactions the algorithm can make. A six time step series of curtailed energy and market price is shown in Fig. 2. Curtailed energy is available only during period 1 .

Starting from a flat schedule with no charging or discharging, the algorithm generates random transactions and tries each one until one is found that increases revenue; this is then added to the charge/discharge schedule. Table 2 gives one example of the first four transactions that could be accepted:

- Transaction 1 stores curtailed energy and will be made regardless of efficiencies as energy to charge the store is

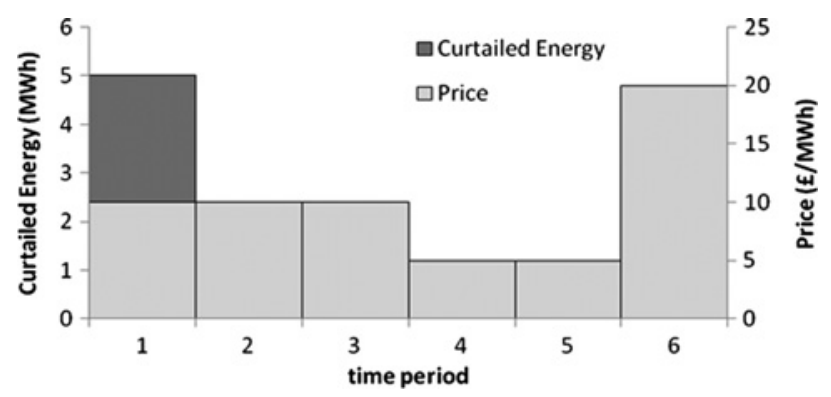

Fig. 2 Time series for illustrative example

Table 2 Possible path for the first four accepted transactions for the optimisation algorithm

\begin{tabular}{llrr}
\hline Transaction & $t_{1}$ & $t_{2}$ & $\Delta E$ \\
\hline 1 & 1 & 4 & 5 \\
2 & 2 & 4 & -5 \\
3 & 3 & 6 & 3 \\
4 & 4 & 5 & -3 \\
\hline
\end{tabular}

available at zero cost, and the sale price of this stored energy will always be positive. This transaction increases revenue over the initial flat schedule but is sub-optimal for two reasons: if periods 2,3 or 6 had been chosen, the sale price would have been higher; secondly the self-discharge reduces the energy available to sell and this loss increases with time so discharging earlier allows more energy to be sold.

- Transaction 2 is an example of a negative energy transaction and moves the sub-optimal discharge from transaction 1 to a period that further increases revenue. In essence it brings forward sale of the energy stored during time period 1 from time period 4 (as per transaction 1) to time period 2.

- Transaction 3 buys additional energy from the market and will only be conducted if the overall efficiency is larger than the ratio of prices in periods 3 and 6 according to (10).

- Transaction 4 increases revenue by moving the charging from transaction 3 forward to a time where the power is cheaper to buy and closer to the discharge time.

Since the algorithm is stochastic, each run of the algorithm will approach the optimum solution via a different path but with enough iterations the same optimal solution will be found.

\section{Active network management case studies}

The ESS model and optimisation algorithm are applied to two case study networks. Case Study 1 is a theoretical case that illustrates the effectiveness of the algorithm at solving problems with non-firm generation and ESS in a number of contexts. Case Study 2 concentrates on the effect that distributed wind and ESSs have on utilisation of the transmission link circuits.

\subsection{Case study 1}

This theoretical network includes local demand ranging from 10 to $50 \mathrm{MW}$, a transmission link circuit of 50 and $60 \mathrm{MW}$ of firmly connected wind; Fig. 3 provides a summary.

A generic ESS unit is modelled with a round-trip efficiency of 0.85 equally split between charging and discharging, and the characteristic time of self-discharge is $2000 \mathrm{~h}$. Several sizes of ESS are simulated; all have the ratio of power to energy capacity of 1:5. The fixed ratio allows simple comparison between sizes of ESS.

The simulation uses data for the period 1 May 2009 30 April 2010. Demand data consist of half-hourly average demands for a rural distribution network in Scotland and has been normalised. Wind data consist of matching half-hourly average generation levels at a wind farm on the same network. The load and wind duration curves for this

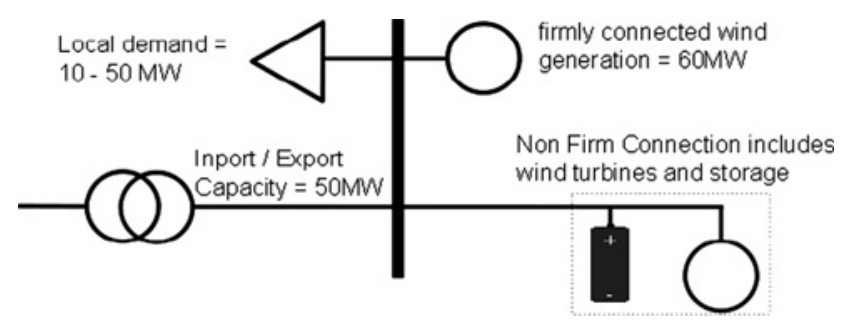

Fig. 3 Single bus representation of case study 1 distribution network 


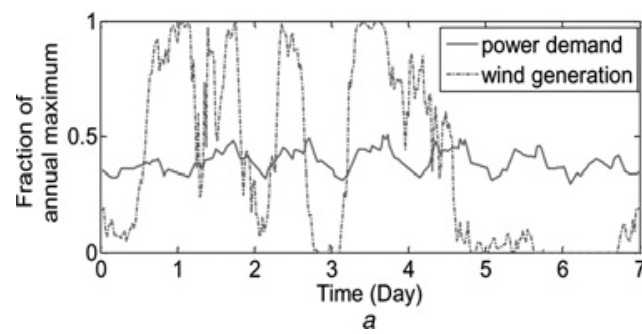

Fig. 4 Example input time series for case study

$a$ 'Wind generation and 'demand' time series for a 7 day period

$b$ Annual demand and generation duration curves

data are shown in Figs. $4 a$ and $b$ show an exemplar 1 week section of the normalised time series. Since distribution networks usually cover relatively small areas, it is assumed that all wind generation on the network follows the same profile. The time-series of the maximum permissible non-firm output is calculated from (2) and forms the non-firm constraint. Market-price data are provided by ELEXON [26] from trades on the UK Power Exchanges [27].

3.1.1 Single wind farm connection: A large wind farm of $25 \mathrm{MW}$ is modelled as the only non-firm generator and the simulation is run multiple times with different penetrations of ESS. With no storage, $11 \%$ of the available generation is curtailed, with the majority occurring during the summer. Fig. 5 shows a 1 week period where curtailment occurs, and the effect of including a $10 \mathrm{MW} / 50 \mathrm{MWh}$ ESS. The non-firm constraint forms the upper bound on the output of the non-firm wind farm and the ESS. Between periods 13,680 and 13,730 the non-firm wind output is curtailed and this energy is available to charge the ESS. The arbitrage operation of the ESS also occurs, for example, twice close to time period 13,640.

For the single wind farm simulations the algorithm convergences occur within $10^{8}$ iterations and this is used for all simulations. The simulations are run on both the Strathclyde and Edinburgh High Performance computers and each one run in approximately $45 \mathrm{~min}$ on a single Intel Xeon X5570 2.93 MHz CPU.

The addition of an ESS increases the revenue received by the wind farm, Table 3 gives values for the total revenue and the revenue increase per MW of ESS. As the size of the ESS unit increases, the total revenue continues to rise, but the rate-per-MW decreases. This law of diminishing

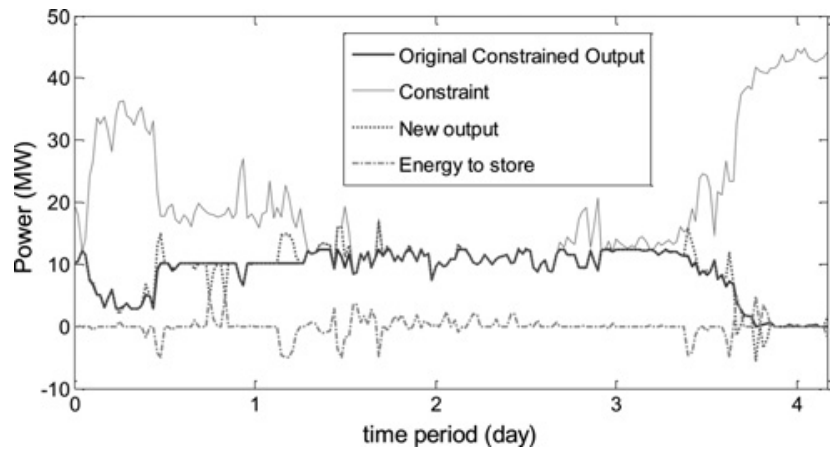

Fig. 5 Section of time-series showing output from a single wind farm

The top line is the network constraint, the initial curtailed output of the non-firm wind farm is shown along with output with the addition of the $10 \mathrm{MW} / 50 \mathrm{MWh}$ ESS

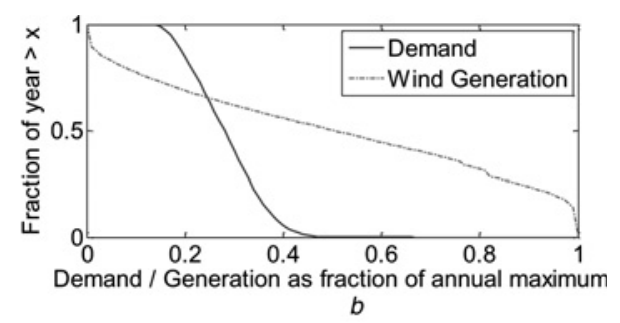

Table 3 Revenue generated by a $25 \mathrm{MW}$ wind farm with ESS over 1 year. Revenue increase values are per MW of storage capacity

\begin{tabular}{lcc}
\hline Scenario & $\begin{array}{c}\text { Total revenue, } \\
£ 10^{6}\end{array}$ & $\begin{array}{c}\text { Revenue increase, } \mathrm{f} / \mathrm{MW} \\
\text { storage }\end{array}$ \\
\hline no storage & 7.10 & - \\
$2 \mathrm{MW} / 10 \mathrm{MWh}$ & 7.34 & 119000 \\
$5 \mathrm{MW} / 25 \mathrm{MWh}$ & 7.65 & 110000 \\
$10 \mathrm{MW} / 50 \mathrm{MWh}$ & 8.08 & 98200 \\
$20 \mathrm{MW} / 100 \mathrm{MWh}$ & 8.81 & 85300 \\
\hline
\end{tabular}

returns occurs because larger stores use more network capacity, and in particular will tend to make maximum use of the network during key periods such as extremes of price. With network capacity fully utilised during these periods, increased ESS capacity unable to access the price peaks/troughs. Similarly, when all the curtailed energy for a particular period has been used, larger ESS units will no longer have access to this.

3.1.2 Modes of operation for ESS operation: The ESS units in the previous simulation combine two separate modes of operation: curtailment-reduction and also arbitrage. The algorithm finds the optimal mix of these two strategies and it is useful to compare this with the revenue generated by operating in each mode independently. To achieve this, the simulation was run three times for a $2 \mathrm{MW} / 10 \mathrm{MWh}$ device and a $25 \mathrm{MW}$ wind farm, firstly, with full functionality, then with arbitrage mode disabled and finally with curtailment reduction mode disabled. From the results presented in Table 4 it is clear that a combination of both modes of operation provides significantly more revenue than either mode operating individually.

\subsubsection{Last-in-first-out (LIFO) curtailment scheme:}

Distribution networks receive many applications for small distributed generation connections and when more than one is connected a 'principles of access' is required. For non-firm connections one such principle is LIFO and is favoured because of its transparency and simplicity $[3,28]$. Under LIFO, the generator first connected to the network

Table 4 ESS revenue when operating in differing modes

\begin{tabular}{lc}
\hline Operating mode & Revenue increase, f/MW \\
\hline no storage & - \\
curtailment-reduction only & 72000 \\
arbitrage only & 87900 \\
curtailment reduction and arbitrage & 119000 \\
\hline
\end{tabular}



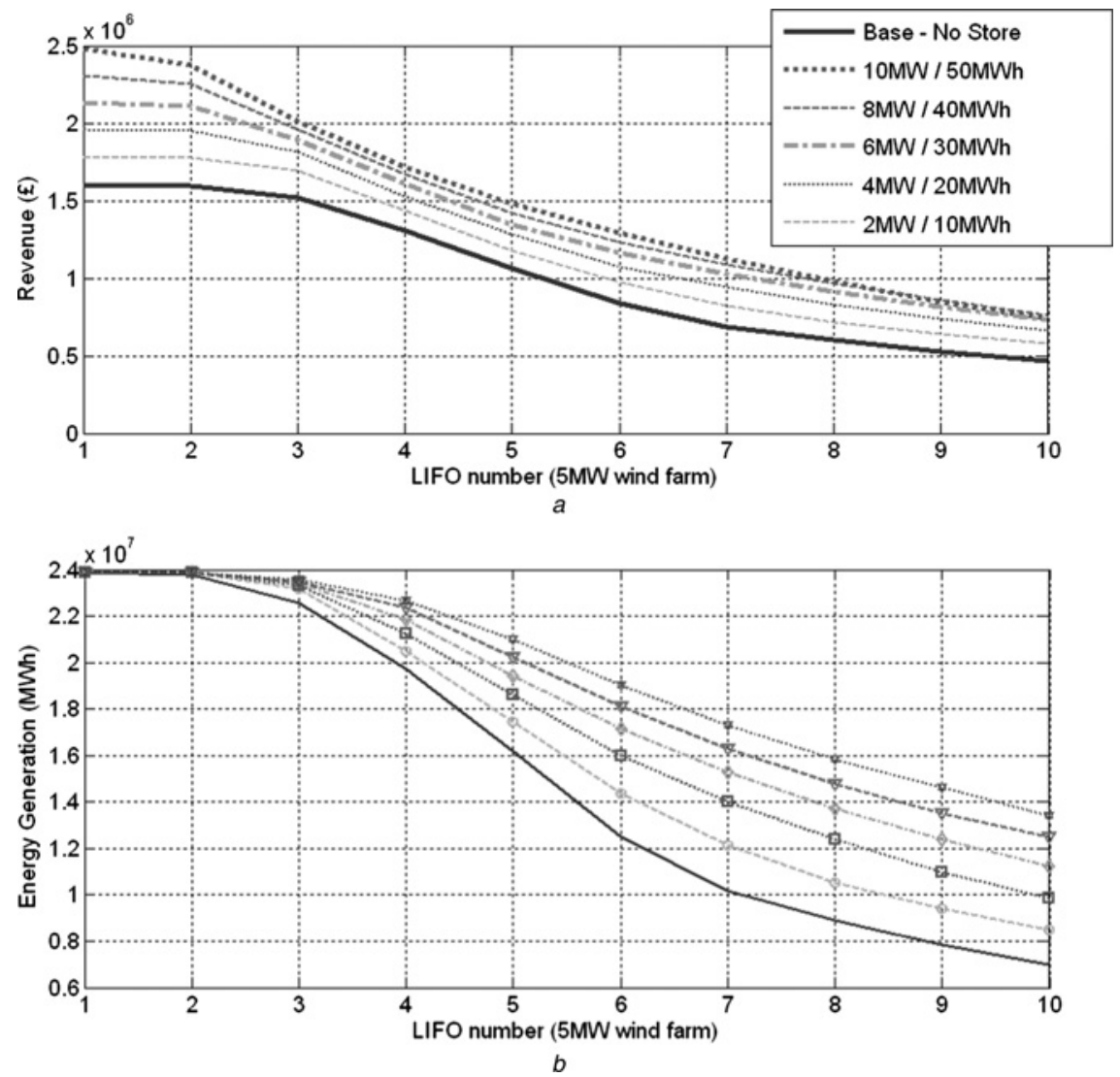

Fig. 6 Revenue and energy production for a LIFO curtailment scheme with $10 \times 5 \mathrm{MW}$ wind farms

$a$ Total revenue

$b$ Total renewable generation

always has priority over others, if there is remaining capacity after the first generator's output, the second connector has priority to use this remaining capacity. Later connectors therefore have less network access and are more likely to be curtailed. In the results below, the LIFO number refers to the order of connection.

A LIFO scheme is modelled with ten $5 \mathrm{MW}$ wind farms and five penetrations of ESS. For any penetration, the same ESS capacity is installed at each wind farm.

Fig. 6 shows energy production and revenue generation from the LIFO scheme. At the first farm (LIFO 1) very little curtailment occurs, only $0.01 \%$ of the possible generation. There is, therefore no increase in energy generation, and the ESS generates revenue almost entirely through arbitrage.

As the LIFO number increases so does the level of curtailment and the ESS has access to greater levels of curtailed generation, this tends to increase revenue as the cost of charging is reduced. Counteracting this trend is the reduced access to network capacity resulting in reduced opportunities for discharge of ESS. This is particularly true during price peaks where ESSs at low LIFO wind farms are likely to use all available network access and ESSs at high LIFO farms will have to export at other times. Increasing the size of ESS does lead to increased generation at every wind farm, however as this means large ESSs at all wind farms, this further restricts network access for high LIFO farms. The effect is most noticeable with the largest ESS units modelled $10 \mathrm{MW} / 50 \mathrm{MWh}$. Here, although the energy generation is increased at all wind farms, revenue generation by LIFO 10 is lower with a 10 MW ESS than with an 8
MW ESS. This is because wind farms LIFO $1-9$ all have larger storage units which fill up the available network capacity.

The simulations show that the incorporation of an ESS in non-firm systems can adversely affect the ability of other generators to raise revenue. This important fact will need to be considered when designing future principles of access for distributed generators and ESS.

\subsection{Case study 2: circuit utilisation}

This case study is based on the rural extra high voltage network from the UK Generic Distribution System project [29]. The parameters of the network are shown in Table 5 and the demand and wind generation data are the same as used for case study 1 . The objective of this case study is to investigate the effect that distributed wind (both firm and non-firm) and ESS have on utilisation of Transmission link circuits.

One advantage of Active Network Management is its ability to increase distributed generation penetration while deferring infrastructure investment. This is achieved through

Table 5 Network characteristics for case study 2.

\begin{tabular}{lr}
\hline Network characteristics & \\
\hline transmission link capacity & $60 \mathrm{MW}$ \\
demand range & $7-39 \mathrm{MW}$ \\
maximum firm DG capacity & $67 \mathrm{MW}$ \\
\hline
\end{tabular}



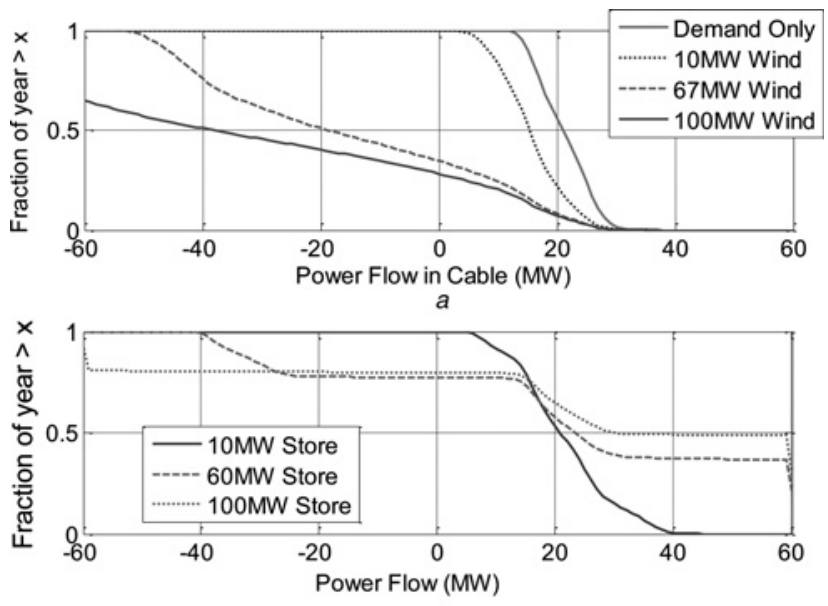

b

Fig. 7 Load duration curves for the transmission link; positive power flow represents importing

$a$ With four levels of total wind penetration and no ESS; $67 \mathrm{MW}$ is the firm limit. The line for $67 \mathrm{MW}$ represents the theoretical firm limit

$b$ With three levels of ESS penetration and no wind

greater utilisation of existing network assets. In this case study, utilisation is defined as the fraction of the year where the power flow in the TLCs is greater than $50 \%$ of its rated capacity, either importing or exporting.

Simulations are carried out for total wind penetrations ranging from 0 to $120 \mathrm{MW}$, the first $67 \mathrm{MW}$ is firmly connected wind. At each wind penetration level, ESS capacity varies from 0 to $100 \mathrm{MW}$. When there is no non-firm wind, the ESS operates only in arbitrage mode as no curtailed energy is available.

The effect of wind penetration on the TLCs is shown in Fig. 7a. With no wind, the circuits import between 7 and 39 MW. As wind penetration increases, the load duration curves move to the left as power flows are reduced and then reversed. Above the limit of firm connections, additional non-firm connections lead to the TLCs exporting at their rated capacity for greater periods of time; generation curtailment ensures that this limit is not breached. Fig. $7 b$ shows similar results for ESS and no wind. Here, the TLCs are utilised at high levels for both importing and exporting. In this situation, the ESS only uses arbitrage. With high penetrations of ESS the export cable is utilised at full capacity in both importing and exporting modes.

Utilisation of the TLCs is shown in Fig. 8. With no ESS and no generation curtailment, maximum utilisation is $36 \%$ which occurs with maximum firm capacity. If $50 \mathrm{MW}$ of additional non-firm wind is added (total wind penetration of $117 \mathrm{MW})$, the utilisation increases to $57 \%$ and the

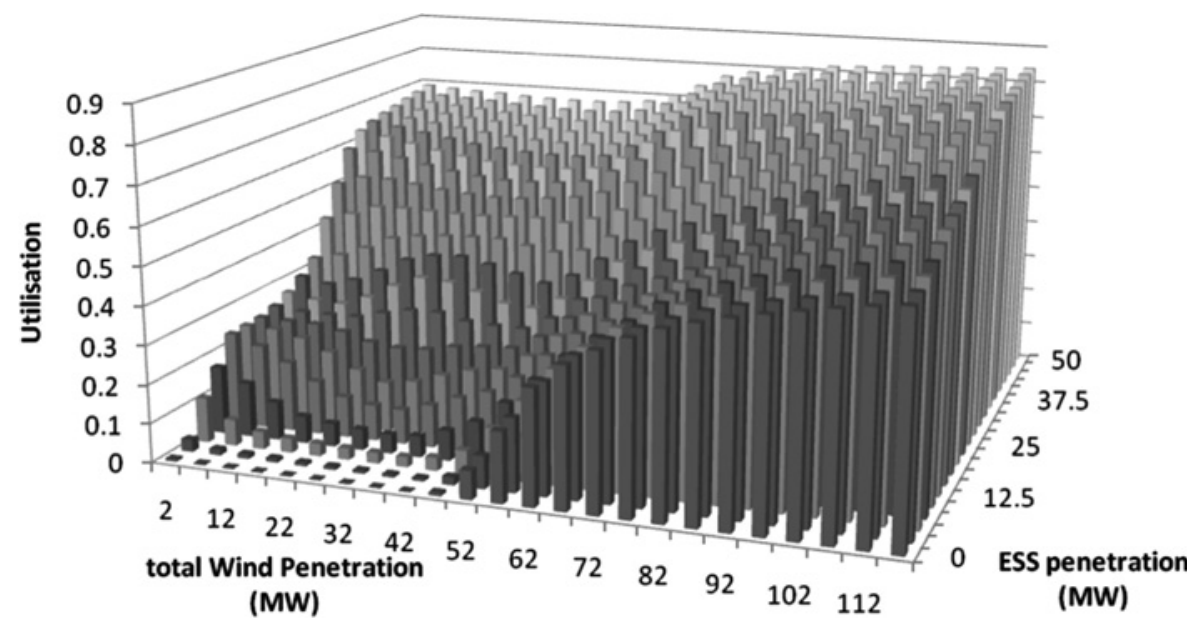

Fig. 8 Circuit utilisation metric based on utilisation greater than 50\% of capacity for all wind and ESS penetration scenarios

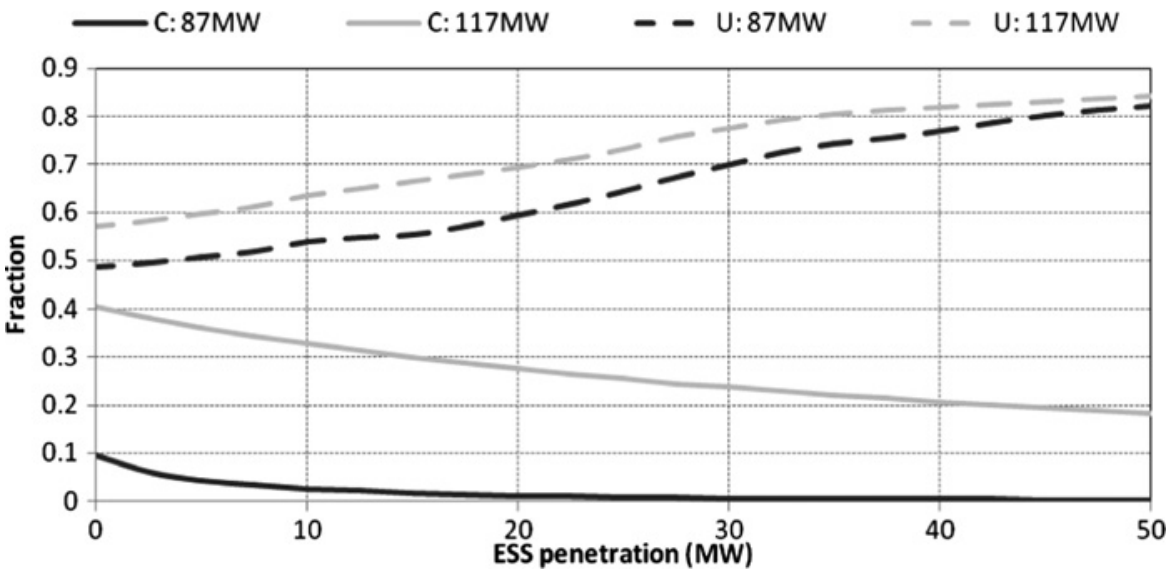

Fig. 9 TLC utilisation $(U)$ and non-firm curtailment (C) for two total wind penetration scenarios with ESS 
www.ietdl.org

Table 6 Total revenue including subsidies and market revenue for four sizes of wind farms [32]

\begin{tabular}{|c|c|c|c|c|c|}
\hline \multirow[t]{3}{*}{ Wind farm size, MW } & \multirow[t]{2}{*}{ Subsidy rates } & \multicolumn{4}{|c|}{$\begin{array}{l}\text { Total annual revenue increase (market revenue + } \\
\text { subsidy), } £\end{array}$} \\
\hline & & \multicolumn{2}{|c|}{$\begin{array}{l}\text { Wind farm side } \\
\text { connection }\end{array}$} & \multicolumn{2}{|c|}{$\begin{array}{l}\text { Network side } \\
\text { connection }\end{array}$} \\
\hline & ESS efficiency: & $85 \%$ & $50 \%$ & $85 \%$ & $50 \%$ \\
\hline 0.1 & FITs: $£ 253 / \mathrm{MWh}+£ 30.1 / \mathrm{MWh}$ export bonus & 7498.6 & 8082 & 7679.4 & 8596.6 \\
\hline 0.5 & FITs: $£ 197 / M W h+£ 30.1 / M W h$ export bonus & 31831 & 33241 & 32732 & 35818 \\
\hline 1.5 & FITs: $£ 99 / \mathrm{MWh}+£ 30.1 / \mathrm{MWh}$ export bonus & 66033 & 61676 & 68746 & 69415 \\
\hline 5.0 & FITS: $£ 46 / M W h+£ 30.1 \mathrm{MWh}$ export bonus & 167130 & 138160 & 176180 & 163980 \\
\hline
\end{tabular}

curtailment of non-firm wind is $40 \%$. If an ESS is then added, the TLC utilisation increases, and curtailment is reduced: with 25MW of ESS, utilisation increases to $73 \%$ and curtailment is reduced to $25 \%$. Fig. 9 shows utilisation and curtailment for two scenarios with non-firm wind connected: these are total wind penetrations of 87 and 117 MW corresponding to non-firm wind capacities of 20 and $50 \mathrm{MW}$, respectively. The graphs show decrease in curtailment and increase in utilisation since ESS penetration is increased.

\section{Discussion}

The case studies presented here illustrate some of the effects that ESS operation is likely to have on a distribution network. Without other regulations, a privately owned ESS is likely to be operated in a manner that maximises revenue from accessible revenue streams. A number of studies $[5,6]$ have suggested that the ability to access multiple revenue streams will be crucial to the financial viability of an ESS on the scale required for bulk energy shifting in distribution networks. Many studies of ESSs have concentrated on optimising their operation for a particular application, but it is important to consider combining several applications. The applications considered here have clearly defined revenue streams. Other applications, while providing value do not provide revenue. For example, in [5] applications with the largest potential value include investment deferral. This is of value to the network, but under existing market rules is unlikely to have an easily accessible revenue stream. For distributed ESSs, many value streams are not available because of minimum size limits. For example, on the UK system the minimum unit size for participation in the fast reserve market is $50 \mathrm{MW} \mathrm{[30].}$

When multiple ESS units are considered, power flows are likely to be significantly altered during key periods such as price spikes when operating in arbitrage mode. The design of networks, including the principles of access to be applied to distributed generation and ESSs will have to be carefully considered. When generators have high priority connections, the addition of an ESS is likely to adversely affect lower priority generators. When investment is made based on likely network availability, these changes can affect business plans and therefore investment decisions.

The algorithm used is heuristic and in the year long simulations convergence occurs within $10^{8}$ iterations. In order to relieve the computational burden, it is possible to use a probability distribution to govern the likely separation between the two randomly selected time periods. In this manner, it can be made more (or less) likely that the second period will lie within a given time interval of the first. This can be used to reduce the number of potential transactions that are unlikely to be accepted. For example, for a small storage system or one with a large rate of self-discharge, storing over very long periods is unlikely to be optimal hence the likely separation of the two periods should be made narrower. Biasing towards shorter separations can raise the probability that a transaction will be accepted and therefore reduce the time to convergence. This will be investigated in future work.

\subsection{Subsidies}

The method described here is based on maximising market revenue. However, in many markets, renewable subsidies for generators form a large percentage of total revenue to wind farms. Where these subsidies are based on energy generation rather than available renewable capacity, ESSs are likely to increase the revenue received from subsidies as well as from the market. In the UK electrical market, wind-generators are able to claim feed-in-tariffs (FITs) for installations up to $5 \mathrm{MW}$ or indeed Renewables Obligation Certificates (ROCs) for larger wind-farm capacities. The revenue from subsidy is a significant factor in financial viability of a wind farm. In 2011, the average ROC price was $£ 47.99 / \mathrm{MWh}$ [31] compared with the spot market average of $£ 41.77 \mathrm{MWh}$ [26].

With FITS this can be even more: for a $100 \mathrm{~kW}$ wind turbine the FITs payments can be $£ 120 / \mathrm{MWh}$ [32]. The subsidy payments for four sizes of wind-farm are shown in Table 6.

The existence of subsidies provides a strong incentive for increasing renewable generation, and can provide additional revenue to an ESS in combination with wind farms. Subsidies are expected to have a distorting effect on the market operation, and the interaction of subsides with the ESS needs careful thought. Under current arrangements FITs and ROCs are paid for increased generation not effective use of generated energy. Connecting an ESS outside of the wind farm meter, but before any network constraint may allow additional subsidies to be claimed before losses in the storage unit. The effect of this would be to encourage inefficient ESSs over efficient devices. For example, to charge an ideal $100 \%$ efficient $10 \mathrm{MWh}$ ESS device requires only $10 \mathrm{MWh}$. However, if the charging efficiency is 0.7 this increases to $14.2 \mathrm{MWh}$, and under the current UK system this additional $4.2 \mathrm{MWh}$ is eligible for subsidy payments as it has passed through the export meter of the generator.

To investigate this effect four additional simulations have been run with small wind farms and an ESS. Wind farm sizes of $100 \mathrm{~kW}, 500 \mathrm{~kW}, 1.5 \mathrm{MW}$ and $5 \mathrm{MW}$ are simulated 
corresponding to four UK subsidy bands. In each case, the original constraint from case study 1 is scaled down until $35 \%$ of generation is curtailed. An ESS is connected with a power capacity of $20 \%$, an energy-to-power ratio of 5 and no self discharge. In all simulations, only increases in renewable generation are eligible for subsidies; arbitrage power can make market revenue, but subsidies are not applied to this.

Table 6 gives a breakdown of the revenue increase due to the ESS units at each wind farm. With small generators, subsidy payments are high. For the 100 and $500 \mathrm{~kW}$ wind farms, the subsidies result in higher overall revenue increases for the $50 \%$ efficient store compared to the $85 \%$ efficient store for ESS units connected either inside the farm or on the network. For the $1.5 \mathrm{MW}$ wind farm, the $50 \%$ efficient ESS has maximum revenue increase only if connected on the network. This is because inside the wind farm it only exports renewable energy after ESS losses. With the $5 \mathrm{MW}$ wind farm, as the subsidy level is low the most efficient store $(85 \%)$ has the greatest revenue increase.

This gives an example of how a combination of ESS and subsidies can lead to undesirable effects. As the use of ESSs to support renewable generation increases, and as energy policy develops particularly with reference to subsidies, careful consideration will need to be given to the way in which subsidies are structured.

\section{Conclusions}

This paper presents an optimisation algorithm for maximising the revenue generated by an ESS trading on the electricity market and utilising curtailed energy. This can be used as a method of benchmarking real-time operational strategies for energy storage.

The algorithm is used to investigate the revenue available in combination with wind-farms in a curtailment scheme. The results show that using a store to combine market-trading and time-shifting creates more revenue than either strategy on its own. In a LIFO curtailment scheme with multiple generators it is noted that the effect on other members of a scheme needs to be considered when allowing storage to connect. A study of the usages of circuits shows that ESS in a curtailment scheme while reducing curtailment, simultaneously increases utilisation of the circuits linking the distribution and transmission systems. Finally, it is shown that renewable subsidies could encourage inefficient ESS technologies through increases in renewable output.

\section{References}

1 Jenkins, N., Allan, R., Crossley, P., Kirschen, D., Strbac, G.: 'Embedded generation' (IEE Press, 2000, London)

2 SSE: 'Facilitate generation connections on Orkney by automatic distribution network management' (Department of Trade and Industry, 2004)

3 Currie, R.A.F., Ault, R.A.F., MacDonald, G.W., J.R.: 'Methodology for determination of economic connection capacity for renewable generator connections to distribution networks optimised by active power flow management', IEEE Proc. Gener., Transm. Distrib., 2006, 153, pp. 456-462

4 Strbac, D., Ramsay, C., Pudjianto, D.: 'Integration of distributed generation into the UK power system' (DTI Centre for Distributed Generation and Sustainable Electrical Energy, 2007)

5 Bloomberg New Energy Finance 'Grid-Scale Energy Storage: State of the Market' presented at Bloomberg New Energy Finance Summit, 2011, available at: http://www.bnef.com/Presentations/download/64, accessed January 2012
6 Beaudin, M., Zareipour, H., Schellenberglabe, A., Rosehart, W.: 'Energy storage for mitigating the variability of renewable electricity sources: an updated review', Energy for Sust. Dev., 2010, 14, pp. 302-314

7 Electric Power Research Institute, 'Electricity energy storage technology options: a white paper on applications, costs and benefits', available at http://www.electricitystorage.org/images/uploads/static_content/technology/ resources/ESA_TR_5_11_EPRIStorageReport_Rastler.pdf, accessed January 2012

8 Poonpun, P., Jewell, W.T.: 'Analysis of the cost per kilowatt hour to store electricity', IEEE Trans. Energy Convers., 2008, 23, pp. 529-534

9 Atwa, Y.M., El-Saadany, E.F.: 'Optimal allocation of ESS in distribution systems with a high penetration of wind energy', IEEE Trans. Power Syst., 2010, 25, pp. 1815-1822

10 http://www.dom.com/about/stations/hydro/bath-county-pumped-storagestation.jsp, accessed January 2012

11 http://www.gvea.com/energy/bess, accessed January 2012

12 DeVries, T., MacDowall, J., Umbricht, N., Linhofer, G.: 'Cold storage. Battery energy storage systems for Golden Valley Electric Assotiations', AAB review, 2004. Available at: http://www.library.abb.com/global/ scot/scot271.nsf/veritydisplay/627968be8161966fc1256e3f004e0366/ \$File/38-43\%20M848.pdf, accessed January 2012

13 http://www.businesswire.com/news/home/20111230005239/en/China'sState-Grid-BYD-Launch-World's-Largest, accessed January 2012

14 Doughty, D.H., Butler, P.C., Akhil, A.A., et al: 'Batteries for large-scale stationary electrical energy storage'. Electrochem. Soc. Interface, 2010, 19, 49

15 http://www.pdenergy.com/press_121310_gillsonions.html, accessed January 2012

16 http://www.zbbenergy.com/, accessed January 2012

17 http://www.mobility.siemens.com/mobility/global/en/urban-mobility/ rail-solutions/railway-electrification/dc-traction-power-supply/Pages/ dc-traction-power-supply.aspx\#Sitras\%20SES\%20-\%20Stationary\% 20energy\%20storage, accessed January 2012

$18 \mathrm{http}: / / w w w . B E A C O N P O W E R . C O M / c o m p a n y /$ stephentown-archives.asp, accessed January 2012

19 http://www.rwe.com/web/cms/en/365478/rwe/innovations/powergeneration/energy-storage/compressed-air-energy-storage/project-adele/, accessed January 2012

20 Crotogino, F., Mohmeyer, K.U., Scharf, R.: 'Huntorf CAES: more than 20 years of successful operation'. Solution Mining Res. Inst. Spring Meeting, Orlando, USA, 2001

21 Luongo, C.A., Baldwin, T., Ribeiro, P., Weber, C.M.: 'A 100 MJ SMES demonstration at FSU-CAPS', IEEE Trans. Appl. Supercond., 2003, 13, pp. 1800-1805

22 Dukpa, A., Duggal, I., Venkatesh, B., Chang, L.: 'Optimal participation and risk mitigation of wind generators in an electricity market', Renew. Power Gener., 2010, 4, pp. 165-175

23 Farhat, I.A., El-Hawary, M.E.: 'Optimization methods applied for solving the short-term hydrothermal coordination problem', Elect. Power Syst. Res., 2009, 79, pp. 1308-1320

24 Barbour, E., Bryden, I.: 'Energy storage in association with tidal current generation systems'. Proc. Institution of Mechanical Engineers, Part A Journal of Power and Energy, 2011, pp. 443-455

25 Barbour, E., Wilson, I.A.G., Bryden, I.G., McGregor, P.G., Mulheran, P.A., Hall, P.J.: 'Towards an objective method to compare energy storage technologies: development and validation of a model to determine the upper boundary of revenue available from electrical price arbitrage', Energy Environ. Sci., 2012, 5, pp. 5425-5436

26 ELEXON, Market Index Data - ELEXON portal website, available at: https://www.bsccentralservices.com/, accessed December 2011

27 ELEXON, 'Market Index Definition Statement for Market Index Data Provider(s)', available at: http://www.elexon.co.uk/ELEXON\% 20Documents/mids_v6.0.pdf2011, accessed January 2012

28 Currie, R., Neill, B., Foote, C., Gooding, A., Ferris, R., Douglas, J. 'Commercial arrangements to facilitate active network management', presented at the CIRED, Frankfurt, Germany 2011

29 The United Kingdom Generic Distribution System. Available at: http:/ www.monaco.eee.strath.ac.uk/ukgds/, accessed January 2012

30 National Grid.Firm Fast reserve Explanation and Tender Guidance Document. Available at: http://www.nationalgrid.com/NR/rdonlyres/ 294F9D55-1EB0-4C31-8840-3BFDD4AB0C12/33092/ FR_Explanation_ Tender Guidance.pdf, accessed December 2011

31 Non-Fossil Purchasing Agency Ltd: ‘e-Rocs Auction Prices', 2011 available at: http://www.e-roc.co.uk/trackrecord.htm, accessed January 2012

32 Feed-In-Tariffs LTD.: 'Tariff Levels Table', available at: http://www. fitariffs.co.uk/eligible/levels/, accessed January 2012 